\title{
Effect of Copper Addition on Pitting Corrosion of MA-Al
}

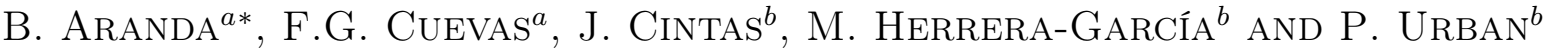 \\ ${ }^{a}$ Escuela Técnica Superior de Ingeniería, University of Huelva, \\ Carretera de Palos s/n, 21819, La Rábida-Huelva, Spain \\ ${ }^{b}$ Escuela Técnica Superior de Ingeniería, University of Seville, \\ Camino de los Descubrimientos s/n, 41092, Sevilla, Spain
}

\begin{abstract}
This paper is intended to highlight the effect of copper addition on the pitting corrosion resistance of aluminium-base powder metallurgy parts. Results obtained on these mechanically alloyed (MA) specimens are compared with parts of MA-Al without added copper, as well as with commercial aluminium alloys. Immersion tests from 2 to 96 hours in $3.5 \% \mathrm{NaCl}$ solutions, and potentiostatic techniques, were used to study the pitting corrosion. It was concluded that copper addition, in a similar way that in commercial aluminium alloys, produces a negative effect on the pitting corrosion resistance, because of the formation of $\mathrm{Al}_{2} \mathrm{Cu}$. These precipitates produce galvanic cells that favour the specimen pit. Therefore, increasing the copper content of $\mathrm{MA}-\mathrm{Al}$, although improving their ductility, worsens the pitting corrosion resistance of these alloys.
\end{abstract}

DOI: 10.12693/APhysPolA.129.788

PACS/topics: $81.20 . \mathrm{Ev}, 82.45 . \mathrm{Bb}$

\section{Introduction}

Research on the mechanical and corrosion properties of aluminium matrix composites has been the subject of numerous studies. Considerable attention is focused on $\mathrm{Al}$ reinforced with high-strength ceramics, because of their superior properties in comparison with most of conventional materials [1-3]. However, the study on corrosion resistance of aluminium base powder metallurgy parts is still under development.

One of the main debilities of MMCs (Metal Matrix Composites) is the influence of the reinforcements on their corrosion resistance. Aluminium and its alloys show a high corrosion resistance in atmospheric conditions; thin and strongly adhering aluminium oxide layer develops a spontaneous protection. The addition of a reinforcing phase could lead to discontinuities in the oxide layer, or the formation of local electrochemical cells with the aluminium matrix. This increases the number of sites where corrosion can be initiated, increasing the probability of severe attack $[4,5]$.

In aggressive media, as marine atmosphere with a high content of chlorides, the aluminium corrosion resistance decreases, because of a severe and highly localized pitting attack. Pitting corrosion is a localized form of corrosion producing small bites in a metal. Corrosion by pitting in aluminium alloys is a very complex process that can be affected by various factors such as the type of aggressive ion and its concentration, type of intermetallics formed, and the electrochemical activity associated with these intermetallics [6-8]. Since it is an electrochemical corrosion, the corrosion potential is defined as the potential at which the anodic and cathodic current densities

*corresponding author; e-mail: beatriz@uhu.es are the same (point of interception between the anodic and cathodic branch in the polarization curves). In this paper, the corrosion potential is calculated at open circuit, and will be the beginning of the cyclic polarization curve. On the other hand, the pitting potential is the potential where this localized attack starts, and it is used to measure the corrosion resistance.

In this work, the effect of copper addition on the pitting corrosion resistance of aluminium-base powder metallurgy (PM) parts is studied and compared with commercial aluminium alloys. In these materials, the existence of the intermetallic $\mathrm{Al}_{2} \mathrm{Cu}$ has a great influence on the development of pitting corrosion.

\section{Experimental}

Atomized elemental aluminium powder (Eckart-Werke, AS 61) of high purity (99.7 wt.\%), 3 wt.\% ethylenebis-stearamide (EBS) wax powder acting as milling process control agent, and $0,0.5,1$ or 2 wt.\% copper powder (Eckart, CH-L10) were used as starting materials. These starting materials were vacuum milled $(5 \mathrm{~Pa})$ in a vertical attritor, rotating at $500 \mathrm{rpm}$, during 10 hours. Milled powders were consolidated by cold uniaxial pressing $(850 \mathrm{MPa})$ and vacuum $(5 \mathrm{~Pa})$ sintering $\left(650^{\circ} \mathrm{C}, 1 \mathrm{~h}\right.$.), followed by furnace cooling. The EBS wax was also used as die-wall lubricant during cold pressing.

Cold pressed cylindrical compacts $(12 \mathrm{~mm}$ in diameter and mass of $4 \mathrm{~g}$ ) were cut into transversal slices 3 to $4 \mathrm{~mm}$ thick, used to study the development of pitting. Samples were mechanically grinded with $\mathrm{SiC}$ up to 2500 grit. Then polished with diamond paste $(3 \mu \mathrm{m})$, and finally with $\mathrm{MgO}$ (Buehler, Magomet) polishing powder till getting a clear definition of the porosity. Cylindrical slices (15 mm in diameter) of commercial 2011-T3 aluminium were also used as starting material, being treated in the same way as cylindrical compacts of MA-Al. 
In order to measure the starting porosity of the different samples, an image analyser (Image-Pro Plus) was used.

Specimens were subjected to pitting in a $3.5 \mathrm{wt} . \% \mathrm{NaCl}$ solution (Merck, 99\%), with different immersion times $(2,5,12,24,48,72$ and $96 \mathrm{~h})$ at room temperature. After exposure, samples were firstly rinsed with water. The formed oxide layer (or corrosion product) on the specimen was cleaned with a solution of $\mathrm{HNO}_{3}[9,10]$, then rinsed with water again, and dried.

Finally, samples were polished with $\mathrm{MgO}$, getting surfaces ready to determine the pitted area by image analysis. The pitted area includes the pores area, which must be subtracted to determine the actual pitting. For each sample, ten images were considered. The information obtained for pits size, area and numbers of pits were averaged over all the images for each sample.

Similarly, a 3.5 wt.\% NaCl solution was the electrolyte used for potentiostatic testing in an electrochemical cell with a three-electrode configuration. A slice of MA-Al or commercial aluminium was used as working electrode, whereas graphite and silver/silver chloride $(\mathrm{Ag} / \mathrm{AgCl})$ electrodes $(3 \mathrm{M} \mathrm{KCl})$ were used as counter and reference electrodes, respectively.

The MA-Al or commercial Al slices were prepared by welding a copper wire to a drilled hole made on one face of the slice; the slice was then cold mounted in resin and dried in air for $24 \mathrm{~h}$ at room temperature. Before measurements, the other face of the working electrode was prepared in the same way as samples for immersion test.

Cyclic polarization curves were obtained after immersion for $1 \mathrm{~h}$ in the aforementioned electrolyte, at a scanning rate of $0.3 \mathrm{mV} / \mathrm{s}$, starting from corrosion potential, until a maximum current of $5 \mathrm{~mA} / \mathrm{cm}^{2}$.

\section{Results and discussion}

Regarding mechanical properties, copper addition does not decrease porosity of PM specimens, but improves mechanical properties. Milling produces an Al-Cu solid solution, resulting after sintering in the formation of second phases. Increasing copper content produces both a progressive hardening and, due to the effect of a liquid phase sintering, a greater ductility of the compacts.

\section{TABLE I}

Porosity (P), Brinell hardness (HB), ultimate tensile strength (UTS) and elongation (E) of sintered compacts with different percentages of copper, and commercial aluminium.

\begin{tabular}{c|c|c|c|c}
\hline \hline Material & P [\%] & Hardness HB & UTS [MPa] & E [\%] \\
\hline $0 \mathrm{Cu}$ & 2.80 & 95 & 278 & 0.5 \\
$0.5 \mathrm{Cu}$ & 3.18 & 99 & 265 & 1.23 \\
$1 \mathrm{Cu}$ & 3.29 & 104 & 268 & 1.67 \\
$2 \mathrm{Cu}$ & 3.17 & 111 & 276 & 2.27 \\
$2011-\mathrm{T} 3$ & 0.17 & 95 & 290 & 12
\end{tabular}

Table I presents mechanical properties of sintered compacts with different percentages of $\mathrm{Cu}$.

The higher hardness and ductility of $2 \mathrm{Cu}$ compacts make them to be considered the ones with the best mechanical properties among PM specimens. On the other hand, as expected, commercial aluminium presents lower porosity and higher elongation than PM compacts.

Regarding corrosion resistance, immersion tests verify a higher susceptibility to pitting corrosion due to higher copper contents and the formation of $\mathrm{Al}_{2} \mathrm{Cu}$ (Fig. 1), acting as cathodic areas and with a mean particle size of $10 \mu \mathrm{m}$. Although copper in solid solution improves aluminium resistance to pitting corrosion $[8,11]$, increasing the copper content leads to the formation of these intermetallics, which are responsible for pitting corrosion [11].

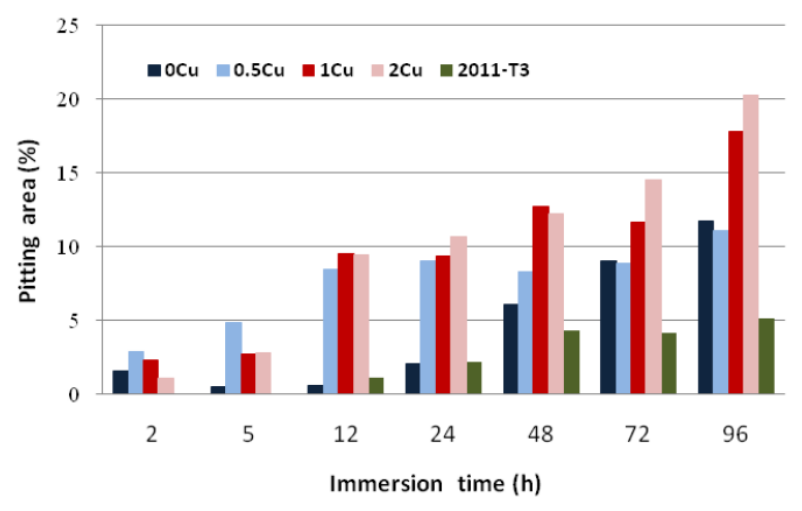

Fig. 1. Pitting area for different immersion times in compacts with different copper content.

Initial porosity of MA-Al compacts with or without copper is similar, however, the pitting area after immersion for $96 \mathrm{~h}$ increases from $11.69 \%$ for $0 \mathrm{Cu}$ to $20.27 \%$ for $2 \mathrm{Cu}$. The pitting area decreases to $5.11 \%$ for commercial aluminium because of the lower initial porosity and higher uniformity of the matrix, despite the higher copper content $(5-6 \%)$.

In compacts without copper, pits evenly distributed in the matrix are produced, growing in number and size with immersion times, as shown in Fig. 2a for $96 \mathrm{~h}$. These pits are due to the matrix dissolution where the formed oxide layer is more easily disrupted because of the presence of cathodic impurities, porosity, etc. In copper containing compacts, dissolved copper after milling precipitates as $\mathrm{Al}_{2} \mathrm{Cu}$, in general, homogeneously distributed in matrix. Therefore, uniform pitting of the $\mathrm{Al}$ matrix is produced by local cells. Also, big pits are observed, mainly for high copper contents, and even after short immersion times. These anodic pits are surrounded by an area almost free of pits, rich in $\mathrm{Al}_{2} \mathrm{Cu}$, which acts as the cathode of the corrosion process (Fig. $2 \mathrm{~b}$ and $2 \mathrm{c}$ ).

The Al matrix pitting is significantly favoured by higher copper contents, even for lower immersion times, which proves the formation of $\mathrm{Al}_{2} \mathrm{Cu}$, acting as cathodic zones in the specimen. 


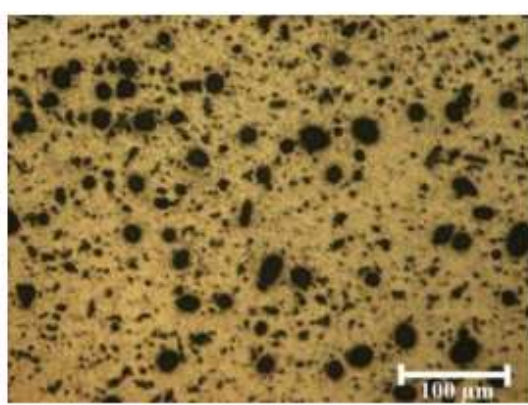

(a)

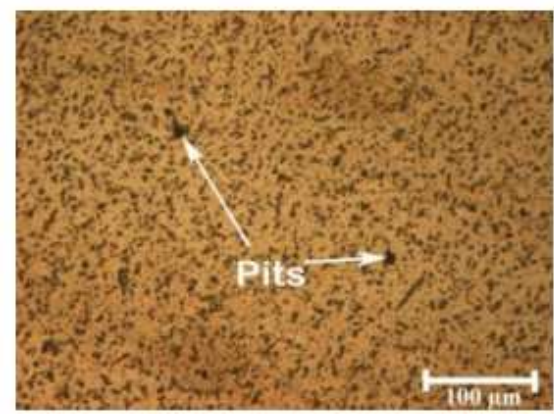

(b)

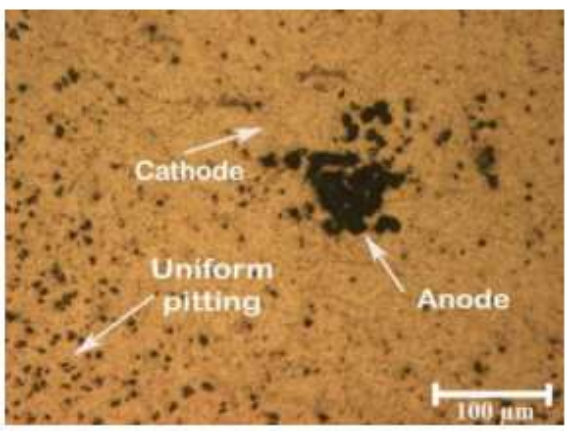

(c)

Fig. 2. Micrograph of compact (a) $0 \mathrm{Cu}$ after $96 \mathrm{~h}$ of immersion, (b) commercial aluminium after $48 \mathrm{~h}$ of immersion, and (c) $2 \mathrm{Cu}$ after $5 \mathrm{~h}$ of immersion.

Figure 3 shows the polarisation curves of MA-Al, with and without copper, and commercial aluminium. The corrosion potential, $E_{\text {corr }}$, of $\mathrm{Cu}$ containing MA-Al compacts, ranges from -0.684 to $-0.704 \mathrm{~V} \mathrm{Ag} / \mathrm{AgCl}$. This shift in the corrosion potential may be attributed to several factors, such as a more uniform corrosion layer and differences in the distribution of the intermetallic compounds. This potential is displaced to more positive values by decreasing the copper content, due to the greater uniformity of the oxide layer and the lower presence of intermetallics. In commercial aluminium, displacement to even more positive values $\left(-0.620 V_{\mathrm{Ag} / \mathrm{AgCl}}\right)$, despite the higher content of copper, is due to the greater uniformity of the oxide layer because of the lower porosity. The rapid increase in current density in the anodic range indicates that the pitting potential, $E_{\text {pit }}$ is close to $E_{\text {corr }}$, and specimens with copper (including commercial aluminium) are freely pitting very near the corrosion potential. However, this is not observed in the sample without copper. The $0 \mathrm{Cu}$ compact presents a pitting potential of -0.636 , which represents a difference with respect to $E_{\text {corr }}$ of 0.240 . The bigger difference between pitting and corrosion potential reflects the lower susceptibility to pitting corrosion in this specimen. Therefore, the corrosion behaviour with respect to $\mathrm{Cu}$ containing compacts is improved, as was shown above by the smaller pitting area.

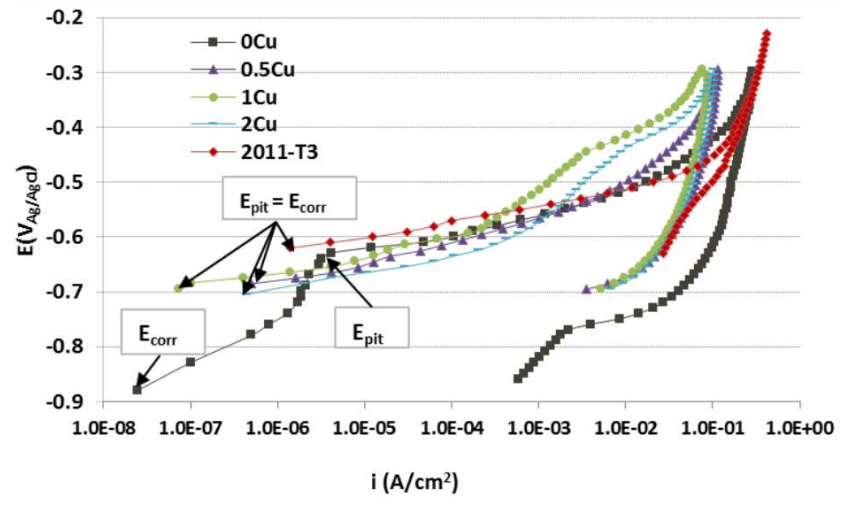

Fig. 3. Polarisation curves of MA-Al, with and without copper, and commercial aluminium.

On the other hand, the specimens with copper show a positive hysteresis, with the pitting potential located at the same position as the corrosion potential. The large area of the hysteresis loop in these materials indicates that they do not exhibit repassivation, but an increase in susceptibility to pitting corrosion, producing new bites or size increase during the reverse scan [8]. Thus, compacts with 1 and 2 wt.\% $\mathrm{Cu}$ show a large area of the hysteresis loop, while commercial aluminium, with less susceptibility to pitting, shows a smaller area.

Other results in the literature $[7,12]$ reveal, as demonstrated in this article, that the presence of intermetallic cathodes, such as $\mathrm{Al}_{2} \mathrm{Cu}$, produces high susceptibility to pitting corrosion. In addition, these studies confirm that the rapid increase in current density in the anodic range indicates that $E_{\text {pit }}$ is close to $E_{\text {corr }}$, and specimens with intermetallic cathodes are easily pitted very near the corrosion potential.

All the above, suggests that the results shown here are in line with the existing literature.

\section{Conclusions}

Susceptibility to pitting corrosion in MA Al-base samples largely depends on the final microstructure, and compositions. Attained results lead to the following conclusions:

- Regarding mechanical properties, tensile strength is in the same order of magnitude for all the studied materials, although the addition of copper improves the ductility in MA-Al. 
- The addition of copper produces a negative effect on the pitting corrosion resistance of Al. This pitting corrosion is produced because of the presence of $\mathrm{Al}_{2} \mathrm{Cu}$ cathodic intermetallics. Both in $\mathrm{PM}$ and commercial aluminium, corrosion is observed. MA-Al without copper has the highest pitting resistance.

\section{Acknowledgments}

The financial support of the Ministry of Science and Innovation through the research project (DPI2012-37948C02-01) is gratefully acknowledged. The authors also wish to acknowledge the support in experimental work of laboratory technicians J. Pinto, M. Sanchez and M. Madrid (University of Seville).

\section{References}

[1] A. Jiménez-Morales, E.M. Ruiz-Navas, J.B. Fogagnolo, J.M. Torralba, Bol. Soc. Esp. Ceram. V 43, 196 (2004).

[2] J. Cintas, J.M. Montes, F.G. Cuevas, E.J. Herrera, Scrip. Mater. 53, 1165 (2005).

[3] A. Włodarczyk-Fligier, M. Adamiak, L.A. Dobrzański, Arch. Mat. Sci. Eng. 42, 29 (2010).
[4] A.J. Trowsdale, B. Noble, S.J. Harris, I.S.R. Gibbins, G.E. Thompson, G.C. Wood, Corr. Sci. 38, 177 (1996).

[5] A. Urena, E. Otero, M.V. Utrilla, P. Rodrigo, Bol. Soc. Esp. Ceram. V. 43, 233 (2004).

[6] B. Zaid, D. Saidi, A. Benzaid, S. Hadji, Corr. Sci. 50, 1841 (2008).

[7] W.R. Osório, C.M. Freire, R. Caram, A. Garcia, Electrochim. Acta 77, 189 (2012).

[8] R. Arrabal, B. Mingo, A. Pardo, M. Mohedano, E. Matykina, I. Rodríguez, Corr. Sci. $\mathbf{7 3}, 342$ (2013).

[9] ASTM, Standard practice for laboratory immersion corrosion testing of metals, G31-72, Annual Book of ASTM Standards, American Society for Testing and Materials, Philadelphia, (2004).

[10] ASTM, Standard for preparing, cleaning and evaluating corrosion test specimens, G1-03, Annual Book of ASTM Standards, American Society for Testing and Materials, Philadelphia, (2003).

[11] R.Z. Nakazato, E.N. Codaro, A.L. Horovistiz, L.R.O. Hein, Prakt. Metall. 38, 74 (2001).

[12] Kyung-Hwan Na, Su-Il Pyun, Corr. Sci. 50, 248 (2008). 